\title{
Peripheral neuropathy in a case with CADASIL: a case report
}

\author{
Yusuke Sakiyama, Eiji Matsuura* (D, Yoshimitsu Maki, Akiko Yoshimura, Masahiro Ando, Miwa Nomura, \\ Kazuya Shinohara, Ryuji Saigo, Tomonori Nakamura, Akihiro Hashiguchi and Hiroshi Takashima
}

\begin{abstract}
Background: Cerebral autosomal dominant arteriopathy with subcortical infarcts and leukoencephalopathy (CADASIL) is characterized clinically by central nervous system dysfunctions. It is unclear whether CADASIL is involved in peripheral neuropathy.

Case presentation: A 67-year-old Japanese man with stepwise progression of sensory and motor neuropathy was admitted to our hospital. Peripheral neuropathy of the extremities was detected through electrophysiological and pathological studies, and brain magnetic resonance imaging revealed bilateral periventricular ischemic and thalamic hemorrhagic lesions. We diagnosed CADASIL after detecting granular osmiophilic material in the walls of the endoneurial vessels morphologically and identifying a heterozygous NOTCH3 mutation p.Arg75Pro.
\end{abstract}

Conclusions: CADASIL is to be included in the work-up of not classified peripheral neuropathies.

Keywords: CADASIL, Peripheral neuropathy, Multiple mononeuropathy, NOTCH3, Granular osmiophilic material (GOM)

\section{Background}

Cerebral autosomal dominant arteriopathy with subcortical infarcts and leukoencephalopathy (CADASIL) is an autosomal dominant disorder. This disease caused by mutations in the Notch 3 gene that encodes a transmembrane protein expressed in vascular smooth muscle cells [1]. CADASIL patients have various clinical symptoms of central nerve systems, such as migraine, recurrent stroke, progressive cognitive decline, and psychiatric disturbance. Because it is unclear whether CADASIL is involved in peripheral neuropathy, we expand the phenotype of CADASIL by reporting electrophysiological and pathological features of CADASIL patient with peripheral neuropathy.

\section{Case presentation}

A 67-year-old man had the first episode of left leg weakness at the age of 65 years and subsequently experienced numbness of the bilateral fourth and fifth fingers (Additional file 1). At the age of 66, he developed right leg weakness and difficulty in walking and was admitted

\footnotetext{
*Correspondence: pine@m.kufm.kagoshima-u.ac.jp Department of Neurology and Geriatrics, Kagoshima University Graduate School of Medical and Dental Sciences, 8-35-1 Sakuragaoka, Kagoshima City, Kagoshima 890-8520, Japan
}

to our hospital. Neurological examination revealed no abnormalities in orientation, memory, or cranial nerves. Mild weakness was noted in the distal muscle of the upper limbs, and pronator drift test was positive in the left upper limb. Lower limb muscle weakness was moderate and particularly noticeable in the left anterior tibialis muscle. Deep tendon reflexes were decreased at the triceps and brachioradialis and absent at the knees and ankles. Babinski sign was positive. Pes cavus and toe clawing were absent. There were no finger tremors. A sensory examination showed bilateral hypoesthesia in the lower leg region, below the knees and bilateral numbness of the fourth and fifth fingers. No abnormalities in the urinary tract were found. The ankle-brachial index of blood pressure was normal. The results of a blood study revealed a mild inflammatory reaction and elevated serum proteinase-3-anti-neutrophil cytoplasmic antibody (PR3-ANCA; $4.0 \mathrm{U} / \mathrm{mL}$; normal range, $<3.5 \mathrm{U} / \mathrm{mL}$ ). Complete blood count and CRP level were normal. His liver and renal function were normal. Blood sugar was $97 \mathrm{mg} / \mathrm{dl}$ and $\mathrm{HbAlc}$ was $6.5 \%$. A nerve conduction study was performed at a skin temperature of approximately $30{ }^{\circ} \mathrm{C}$ (Table 1 ). Distal motor and sensory nerve palm latency (DL) were prolonged in the left median nerve, and a slight decrease in 
Table 1 Summary of electrophysiological data on first admission

\begin{tabular}{|c|c|c|c|c|}
\hline \multirow{2}{*}{\multicolumn{2}{|c|}{ (mc) }} & Left median & Left ulnar & Left tibial \\
\hline & $\mathrm{DL}$ (ms) & 4.7 & 3.9 & 3.7 \\
\hline \multicolumn{2}{|c|}{ CMAP (mV) dis./prox. } & $6.1 / 5.4$ & 4.5/N.D. & $12.6 / 8.8$ \\
\hline \multicolumn{2}{|l|}{$\mathrm{MCV}(\mathrm{m} / \mathrm{s})$} & 53.0 & & 43.4 \\
\hline \multicolumn{2}{|c|}{ F-latency (ms) } & 28.4 & 29.7 & 51.8 \\
\hline \multicolumn{2}{|c|}{ F-frequency (\%) } & 100 & 68 & 100 \\
\hline & Left median & Left ulnar & Left sural & Right ulnar \\
\hline $\operatorname{SNAP}(\mu \mathrm{V})$ & 9.3 & N.D. & 6.9 & N.D. \\
\hline $\mathrm{SCV}(\mathrm{m} / \mathrm{s})$ & 44.2 & & 43.9 & \\
\hline
\end{tabular}

$D L$ distal latency, CMAP compound muscle action potential, $M C V$ motor conduction velocity, SNAP sensory nerve action potential, SCV sensory conduction velocity. N.D. not detected

sensory conduction velocity (SCV) was noted. Compound muscle action potentials (CMAP) at stimulation points above the elbow and sensory nerve action potentials (SNAP) were undetectable in the left ulnar nerve. These electrophysiological abnormalities were consistent with multiple mononeuropathy. Brain magnetic resonance imaging showed asymptomatic multiple cerebral infarctions and multiple micro-bleeding lesions in the white matter (Fig. 1). His symptoms did not improve after methylprednisolone pulse therapy and oral prednisolone (30 mg/day) and azathioprine (50 mg/day) therapies.
The pathological findings of a right sural nerve showed neither inflammatory cells around vessels nor any rupture of the inner elastic plate. The loss of smaller fibers and thickening of the blood vessel wall were not observed. Electron microscopy showed granular osmiophilic material (GOM) in the wall of endoneurial small vessels, which indicated peripheral neuropathy resulting from CADASIL (Fig. 2). The heterozygous missense mutation p.Arg75Pro was detected in exon 3 of the NOTCH3 gene in the leukocyte DNA of the patient. No family history displayed cerebrovascular diseases or peripheral neuropathies. His father was diagnosed as heart failure of unknown etiology.

There was no history of smoking or drinking.

\section{Discussion and conclusion}

We successfully diagnosed CADASIL in a Japanese case with peripheral neuropathy and the p.Arg75Pro mutation of the NOTCH3 gene. The pathogenic mutation was previously reported as a cause of CADASIL in Japanese and Korean patients [2, 3] and most frequently found in Japanese patients with CADASIL. None of Japanese cases had peripheral neuropathy [4]. The pathophysiological mechanisms of brain lesions in CADASIL remain unclear. GOM accumulation in the small arterioles of the brain is a pathological feature of CADASIL [1].
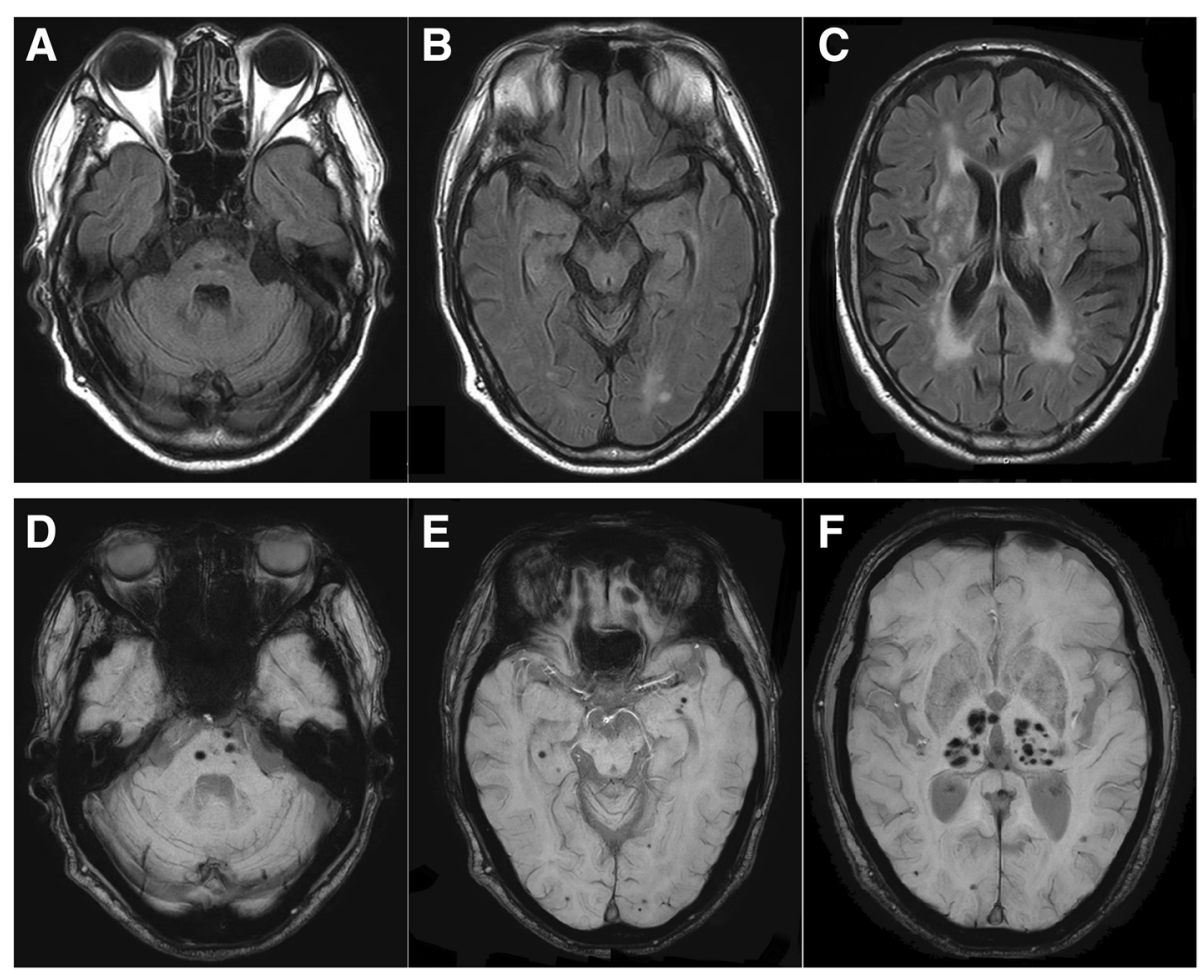

Fig. 1 Brain-MRI findings of our patient. a-c Axial FLAIR image showing the bilateral ischemic lesions in pons, periventricular white matter and deep white matter. $\mathbf{d}$-f: Axial susceptibility-weighted imaging (SWI) showing multiple micro-bleeding lesions in pons, bilateral subcortical white matter and bilateral thalamus 


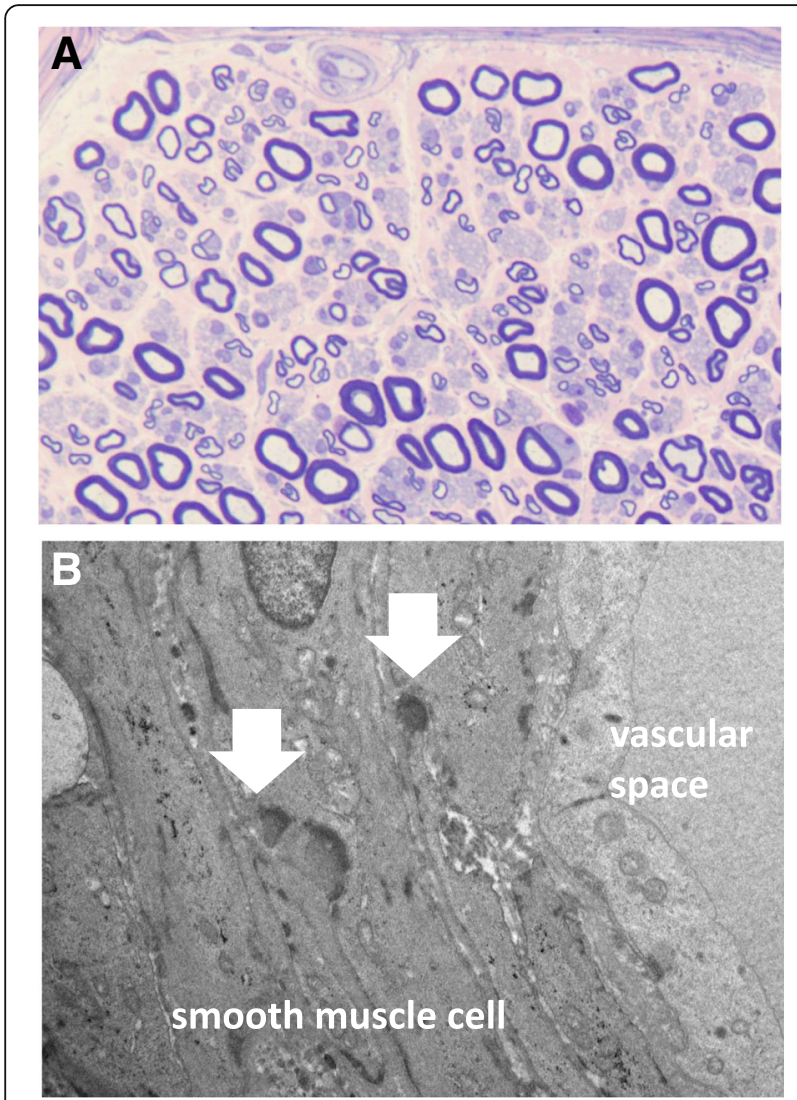

Fig. 2 Pathological investigations on right sural nerve biopsy. The density of myelinated fibers slightly reduced $\left(7303 / \mathrm{mm}^{2}\right.$; normal range $7500-11,000$ fibers $/ \mathrm{mm}^{2}$ ), mostly damaged those of large diameter. a: Toluidine blue-stained semithin epon section. Some axon with thickest myelin and myelin ovoids appeared, suggesting axonal degeneration. Demyelinated fiber was absent. There were no inflammatory cell and subperineurial edema. b: Electron microscope study. Granular osmiophilic material (arrows) was viewed in the electron microscope, deposited between the smooth muscle cells surrounding a small artery in epineurial connective tissue

Notch3 is predominantly expressed in vascular smooth muscle cells in adults [1, 5]. Previous immunoelectron microscopic examination revealed aggregated Notch3 protein in proximity to GOM deposits; however, it is unclear whether Notch3 protein is included in GOM [6-8]. While peripheral neuropathy is usually not seen in the patients with CADASIL, a few previous studies reported the association between CADASIL and peripheral neuropathy [5]. The study suggested axonal damage in peripheral nerve with clinical and electrophysiological findings. Our electron microscopic study revealed the deposition GOM in the wall of endoneurial small vessels in the peripheral nerve. Electrophysiological study showed multiple mononeuropathy, suggesting vascular dysfunction, while there was no inflammatory cell infiltration in the biopsied nerve. Novel protein-protein interactions caused by NOTCH3 mutations has been suggested in vascular function. The dysfunction of blood vessels may induce hemodynamic abnormalities with low-grade chronic ischemia in peripheral nerves [5, 9]. We excluded other causes of chronic progressive axonal neuropathy, including of diabetes mellitus neuropathy, alcoholic neuropathy, ANCA-associated vasculitis, and drug or toxin.

To investigate the frequency of CADASIL in the patients with peripheral neuropathy, we performed genetic analysis of 434 patients of clinically suspected hereditary neuropathy by whole exome sequencing. However, NOTCH3 pathogenic mutation was not found among the patients. In the previous study of CADASIL cases with peripheral neuropathy, subcortical infarcts and/or leukoencephalopathy were detected by brain MRI [5]. In other words, CADASIL cases presenting just with peripheral neuropathy have abnormal lesions in brain MRI. Although we didn't detect NOTCH3 mutation in the patients with hereditary neuropathy, the patients with neuropathy and brain lesions have better to be analyzed for the NOTCH3 mutation.

In conclusion, CADASIL is to be included in the work-up of not classified peripheral neuropathies. Brain MRI and NOTCH3 gene analysis may provide a definite diagnosis for these neuropathies.

\section{Additional file}

Additional file 1: Time line. (DOCX $12 \mathrm{~kb})$

\section{Abbreviations}

CADASIL: Cerebral autosomal dominant arteriopathy with subcortical infarcts and leukoencephalopathy; CMAP: Compound muscle action potentials: CRP: C-reactive protein; DL: Distal latency; GOM: Granular osmiophilic material; PR3-ANCA: Proteinase-3-anti-neutrophil cytoplasmic antibodies; SCV: Sensory conduction velocity; SNAP: Sensory nerve action potentials

\section{Acknowledgments}

We thank Noriko Hirata for excellent technical assistance. The authors would like to thank Enago (www.enago.jp) for the English language review.

\section{Funding}

This work was supported by grants from the Nervous and Mental Disorders and Research Committee for Applying Health and Technology of the Ministry of Health, Welfare and Labour, Japan.

\section{Authors' contributions \\ YS was a major contributor in writing the manuscript. EM and HT revised the manuscript for important intellectual content. EM analyzed the pathological findings. AY and MA performed the genetic examination. YM, MN, KS, RS, TN and $\mathrm{AH}$ gave the clinical information containing medical history, neurological findings, hematological examination, electrophysiological evaluation and treatment. All authors read and approved the final manuscript.}

\section{Ethics approval and consent to participate}

The Institutional Review Board of Kagoshima University approved this study.

\section{Consent for publication}

Written informed consent was obtained from the patient for publication of this Case report and any accompanying images.

\section{Competing interests}

The authors declare that they have no competing interests. 


\section{Publisher's Note}

Springer Nature remains neutral with regard to jurisdictional claims in published maps and institutional affiliations.

Received: 8 June 2018 Accepted: 17 August 2018

Published online: 31 August 2018

\section{References}

1. Chabriat H, Joutel A, Dichgans M, Tournier-Lasserve E, Bousser MG. Cadasil. Lancet Neurol. 2009;8(7):643-53.

2. Mizuno $T$, Muranishi M, Torugun $T$, Tango $H$, Nagakane $Y$, Kudeken $T$, Kawase Y, Kawabe K, Oshima F, Yaoi T, et al. Two Japanese CADASIL families exhibiting Notch3 mutation R75P not involving cysteine residue. Intern Med. 2008;47(23):2067-72.

3. Kim Y, Choi EJ, Choi CG, Kim G, Choi JH, Yoo HW, Kim JS. Characteristics of CADASIL in Korea: a novel cysteine-sparing Notch3 mutation. Neurology. 2006:66(10):1511-6.

4. Ueda A, Ueda M, Nagatoshi A, Hirano T, Ito T, Arai N, Uyama E, Mori K, Nakamura M, Shinriki S, et al. Genotypic and phenotypic spectrum of CADASIL in Japan: the experience at a referral center in Kumamoto University from 1997 to 2014. J Neurol. 2015;262(8):1828-36.

5. Sicurelli F, Dotti MT, De Stefano N, Malandrini A, Mondelli M, Bianchi S, Federico A. Peripheral neuropathy in CADASIL. J Neurol. 2005;252(10):1206-9.

6. Joutel A, Favrole P, Labauge P, Chabriat H, Lescoat C, Andreux F, Domeng $V$, Cecillon M, Vahedi K, Ducros A, et al. Skin biopsy immunostaining with a Notch3 monoclonal antibody for CADASIL diagnosis. Lancet. 2001; 358(9298):2049-51.

7. Joutel A, Andreux F, Gaulis S, Domenga V, Cecillon M, Battail N, Piga N, Chapon F, Godfrain C, Tournier-Lasserve E. The ectodomain of the Notch3 receptor accumulates within the cerebrovasculature of CADASIL patients. J Clin Invest. 2000;105(5):597-605.

8. Ishiko A, Shimizu A, Nagata E, Takahashi K, Tabira T, Suzuki N. Notch3 ectodomain is a major component of granular osmiophilic material (GOM) in CADASIL. Acta Neuropathol. 2006;112(3):333-9.

9. Schroder JM, Zuchner S, Dichgans M, Nagy Z, Molnar MJ. Peripheral nerve and skeletal muscle involvement in CADASIL. Acta Neuropathol. 2005;110(6):587-99.

Ready to submit your research? Choose BMC and benefit from:

- fast, convenient online submission

- thorough peer review by experienced researchers in your field

- rapid publication on acceptance

- support for research data, including large and complex data types

- gold Open Access which fosters wider collaboration and increased citations

- maximum visibility for your research: over $100 \mathrm{M}$ website views per year

At BMC, research is always in progress.

Learn more biomedcentral.com/submissions 